OPEN ACCESS

Edited by:

Mattia Squarcia,

Hospital Clínic de Barcelona, Spain

Reviewed by:

Xudong Shen,

Guizhou Medical University, China

Kun Yan,

Peking University Cancer Hospital,

China

Ernest Belmonte,

Hospital Clínic de Barcelona, Spain

${ }^{*}$ Correspondence:

Xiang Jing

dr.jingxiang@aliyun.com

Specialty section:

This article was submitted to

Cancer Imaging and Image-directed Interventions,

a section of the journal

Frontiers in Oncology

Received: 04 March 2020 Accepted: 22 September 2020

Published: 20 October 2020

Citation:

Jing X, Zhou Y, Ding J, Wang Y, Qin Z,

Wang $Y$ and Zhou $H$ (2020) The Learning Curve for Thermal Ablation of Liver Cancers: 4,363Session Experience for a Single Central in 18 Years.

Front. Oncol. 10:540239. doi: 10.3389/fonc.2020.540239

\section{The Learning Curve for Thermal Ablation of Liver Cancers: 4,363- Session Experience for a Single Central in 18 Years}

\author{
Xiang Jing ${ }^{1,2 *}$, Yan Zhou ${ }^{1,2}$, Jianmin Ding ${ }^{1,2}$, Yijun Wang ${ }^{2,3}$, Zhengyi Qin ${ }^{4}$, \\ Yandong Wang ${ }^{1,2}$ and Hongyu Zhou ${ }^{1,2}$
}

${ }^{1}$ Department of Ultrasound, Tianjin Third Central Hospital, Tianjin, China, 2 Tianjin Institute of Hepatobiliary Disease, Tianjin Key Laboratory of Extracorporeal Life Support for Critical Diseases, Artificial Cell Engineering Technology Research Center, Tianjin Third Central Hospital, Tianjin, China, ${ }^{3}$ Department of Hepatobiliary Surgery, Tianjin Third Central Hospital, Tianjin, China, ${ }^{4}$ Department of Ultrasound, The Third Central Clinical College of Tianjin Medical University, Tianjin, China

This study aimed to explore the special efforts required to achieve proficiency in performing thermal ablation of liver cancers, including tumors in difficult locations, and clarify the effects of handing-down teaching on the corresponding process. Major complications of patients receiving percutaneous thermal ablation of liver cancer were analyzed. Polynomial fitting was used to describe the connection between major complication rates and special experience. Learning curve of major complications was plotted both for the whole group and for each operator, respectively. Tumors in difficult locations were further studied. A total of 4,363 thermal ablation sessions were included in this study. 143 of 4,363 patients had major complications, corresponding to an incidence rate of $3.27 \%$. 806 thermal ablation sessions were performed for tumors in difficult locations. The major complication rate of these sessions is $6.33 \%$. According to the trend of the learning curve of the 4363 patients, the experience of the whole group can be classified into five stages, that is, the high-risk, relatively stable, unstable, proficient and stable periods. A learning curve for an individual operator can be classified into the highrisk, proficient and stable periods. The major complication rates for the chronologically first, second and third operator of the group are 3.23, 3.35, and 3.31\%, respectively. The special experience needed to bypass the first stage corresponds to 410, 510, and 440 sessions, the second stage, 1850, 850, and 870 sessions, by the three operators, respectively. The major complication rates for the tumors in difficult locations for the first, second and third operator were $7.04,5.53$, and 5.98\%, respectively. For the tumors in difficult locations, the special experience needed to bypass the first stage corresponds to 150,130 , and 140 sessions, the second stage, 290, 175, and 185 sessions, by the three operators, respectively. In conclusion, the learning process of an operator percutaneous 
thermal ablation for liver cancer can be classified into three stages. The major complication rate for tumors in difficult locations were higher than that for all tumors. Handing-down teaching can make an operator arrive at the third stage earlier but not the second stage.

Keywords: learning curve, thermal ablation, liver cancer, major complication, handing-down teaching

\section{INTRODUCTION}

Local thermal ablation techniques-including radiofrequency ablation, microwave ablation, laser ablation, and high intensity focused ultrasound (HIFU)-is widely used for the treatment of liver tumors in clinical practice (1-3). Among them, radiofrequency and microwave ablation are the most popular techniques $(4,5)$. Patients with liver cancer benefit significantly from the minimally invasive therapy. Previous studies show that the long-term outcome of patients treated by thermal ablation is comparable with that of surgical resection $(6,7)$. The major complications and perioperative mortality, however, were significantly lower in patients undergoing local thermal ablation $(8,9)$.

Major complication is a highly concerned evaluating indicator for thermal ablation. Although major complication may occur occasionally, an experienced operator, advanced equipment and use of assisting methods may help to significantly reduce the risk of major complication. Previous studies found that the rate of complication for thermal ablation ranges from 1.3 to $10.0 \%(10-13)$. With the increase of special experience and the development of equipment, the rate of complication will decrease. However, the major complication rates in different hospitals, countries, and areas are distinct (1215). Therefore, similar to other minimally invasive treatments, thermal ablation for liver cancers is experience-dependent.

Thermal ablation is often regarded as a simple technique of inserting a needle to "burn" the tumor, without getting much attention to the details, assisting methods and skills. Despite minimal invasion of thermal ablation, its major complication is non-trivial and sometimes may lead to death $(16,17)$. Avoiding major complication by improving the special skill of the operators, therefore, is crucial. However, to our best knowledge, there is a lack of extensive study about the special efforts required to achieve proficiency in performing thermal ablation and reduce major complication.

A few studies have explored the learning process of the early period of thermal ablation (18-20). However, the number of patients enrolled in previous studies is small, which is far from sufficient to investigate the connection between special experience and possible major complication, with the rate of the latter being $2.0-4.0 \%(11,13)$.

To bridge the aforementioned gap, in this paper, we studied the learning curve for thermal ablation of more than 4,000 sessions of liver cancers in our central. The effect of handingdown teaching on accelerating the learning process is clarified. Moreover, the special efforts required for treating tumors in difficult location are discussed.

\section{MATERIALS AND METHODS}

\section{Patients}

The clinical data of patients undergoing thermal ablation for liver cancer from December 2001 to December 2019 were analyzed. The aim of all the thermal ablation is the radical treatment. The recommended indications for thermal ablation in our central were (1) patients having a solitary tumor with a size of $\leq 5 \mathrm{~cm}$ or multiple tumors (no more than 5) with a maximum size of $\leq 3 \mathrm{~cm}$; (2) patients without portal vein tumor thrombus or extrahepatic metastasis; (3) patients with liver function of a Child-pugh classification A or B; (4) patients with a platelet count of $\geq 50 \times 10^{9} / \mathrm{L}$ or INR $\leq 1.7$. For patients that do not meet the aforementioned criteria, thermal ablation was decided on a case-by-case basis by the clinician. For patients with liver dysfunction or coagulation disorders, radical thermal ablation was performed after the liver function or coagulation function was improved. Patients (1) receiving thermal ablation for benign tumors, (2) receiving laparoscopic-assisted or open thermal ablation, or (3) undergoing thermal ablation combined with liver resection were excluded. A total of 4,363 patients with 4,363 percutaneous thermal ablation sessions were included in this study.

\section{Equipment}

RFA procedures were performed using mono-polar RFA with cooled-shaft needles or umbrella electrodes without cooled-shaft needles (Mianyang Lide electronics co. LTD, Mianyang, China). The length of the electrodes ranged from 15 to $20 \mathrm{~cm}$ with a 2 - or $3-\mathrm{cm}$ active tip. The power was $200 \mathrm{~W}$, and the frequency was $480 \mathrm{kHz}$. Cool-tip RFA system (Radionics, Burlington, MA, US) and RITA RFA system (Angio Dynamics. US) were adopted.

MWA procedures were carried out using an MTC-3 or MTC3CA microwave therapy instrument (Forsea Microwave \& Electronic Research Institute, Nanjing, China) with a frequency of 2,450 MHz. The MW antenna was a $14 \mathrm{G}$ unipolar cooledshaft needle with a $15-\mathrm{cm}$ length and a $1.5-\mathrm{cm}$ long active tip.

The ultrasound systems used for guidance were ALOKA5000 (Aloka, Tokyo, Japan), Philips iU22, Philips IU Elit, and Philips epic7 (Philips, Bothell, WA, USA), having a convex array probe with a frequency of 1.0-5.0 MHz.

\section{Ablation Procedures}

Different ablation strategies were used depending on the size, morphology, and location of the tumor. Generally, for tumors $\leq 2$ $\mathrm{cm}$, single-point ablation was performed, whereas for tumors $>2 \mathrm{~cm}$, multi-point overlapping ablation was conducted. In addition, the safe margin for complete ablation of the tumor 
was $0.5 \mathrm{~cm}$, unless the tumor was in a difficult location. Before 2005 , the immediate efficacy was assessed based on the hyperechoic region covering the tumor or the clinical experience of the operator. After 2005, CEUS was performed 15 to $20 \mathrm{~min}$ after thermal ablation to determine the immediate efficacy. For residual tumors determined by CEUS, supplementary ablation was performed. All the patients received contrast enhanced CT/ MR to evaluate complete ablation one month after thermal ablation. All the treatments were performed by X. Jing, J. Ding, or Y. Wang individually. Among them, X. Jing was the first operator in our central, and J. Ding and Y. Wang was the second and third. The last two operators had more than 3-year experience of interventional ultrasound and more than 1,000 ultrasound guided procedures before doing thermal ablation. All the treatments were performed by free hand.

\section{Definition of Tumor Located in Difficult Locations}

We defined a tumor in difficult location if the tumor is (1) within $5 \mathrm{~mm}$ from important tissues or organs (including diaphragm, gallbladder, biliary tract, large vessels, right kidney, and gastrointestinal tract), (2) within $5 \mathrm{~mm}$ from the liver capsule, and (3) an exophytic tumor.

\section{Ancillary Protocols for Tumors in Difficult Locations}

(1) Artificial Ascites and Difficult Locations: For tumors adjacent to the extrahepatic tissues or organs, percutaneous puncture catheter drainage was conducted by inserting a $21 \mathrm{G}$ or $18 \mathrm{G}$ PTC needle into the adjoining site. If the adjoining site can restore water, then production of artificial ascites was undertaken. If the adjoining site cannot restore water, then the tissues or organs were prevented from thermal damage by dropping the ice saline solution continuously.

(2) Arterial Hydrothorax: For tumors adjacent to diaphragm or located at liver dome, percutaneous puncture catheter drainage was conducted by inserting an 18 G PTC needle into the pleural cavity. Then, $100-500 \mathrm{~mL}$ of fluid was injected into the pleural cavity to obtain the safe and clear puncture path.

(3) Thermal Ablation Combined With PEIT: For tumors adjacent to the large vessels or biliary tract, a 21 G PTC needle was inserted into the side of the tumor close to the vessel or tract. Then, $1-3 \mathrm{~mL}$ dehydrated alcohol was injected into the tumor. The injection of dehydrated alcohol and the thermal ablation were started at the same time.

(4) Tumor Blood Vessel Block: For exophytic tumors, the antenna or elector was inserted into the tumor blood vessel under the guidance of ultrasound or contrast enhanced ultrasound by passing through a portion of normal liver tissue. (If it cannot be performed, then the antenna was inserted into tumor directly). Then, the ablation was performed with a high power until the tumor presents as hypovascularity on CEUS.
(5) Thermal Ablation Combined With TACE: For tumors with a size of $\geq 5 \mathrm{~cm}$ or with arteriovenous fistula, TACE was performed 1 or 2 weeks before thermal ablation. When the blood supply of the tumor was reduced and the patient was with liver function of a Child-pugh classification A or B, the radical thermal ablation was conducted.

(6) Image-Fusion and Navigation Systems: For lesions invisible on US and CEUS but detected by CECT or CEMRI, the antenna or elector was inserted under the guidance of US/ CEUS-CECT/CEMRI fusing imaging.

It should be noted that in the early period of the development of our group, the same strategy (without assisting method or combined therapy) was performed for all the tumors, no matter whether they located in difficult location or not, because the aforementioned ancillary protocols were not established.

\section{Classification of Complications}

Complications after thermal ablation were assessed according to the clinical symptoms, imaging findings and results of laboratory examinations. The definition of a major complication was a complication that requires further treatment, threatens the life of the patient, leads to substantial morbidity and disability, or results in a lengthened hospital stay (21). All other complications were considered to be minor.

\section{Calculation of Learning Curve}

The learning curves were calculated for the entire group and each operator, respectively. All the tumors and tumors in difficult locations were considered, respectively. The major complication rates were calculated based on moving averages of 50 samples. Polynomial fitting was used to describe the relationship between major complication rates and special experience. The periods of learning curve were identified based on the trend of the curve and the major complication rates. Complication rates of 4 and $2 \%$ were the cut-off values for identifying periods of the learning curves of all ablation sessions. Complication rates of 6 and $4 \%$ were the cut-off values for identifying periods of the learning curves of ablation sessions of tumors in difficult locations.

\section{Statistical Analysis}

Continuous variables are expressed as the mean \pm standard error and categorical variables as frequencies and percentages. The $x^{2}$ test or Fisher test was used to compare categorical data between different groups. For all tests, a $p$ value $<0.05$ was considered to indicate statistical significance. Statistical analyses were performed using the SPSS software (Version 17.0, IBM, Armonk, NY, USA).

\section{RESULTS}

A total of 4,363 patients undergoing percutaneous thermal ablation were included in this study. 143 of 4,363 patients had major complications with an incidence rate of $3.27 \%$ (Table 1). Six patients had a combined major complication. A total of 149 major complications occurred. Eight patients died during the 
TABLE 1 | Major complications after thermal ablation.

\begin{tabular}{lc}
\hline Complication & No. of complications \\
\hline Hemorrhage & 14 \\
Intra-hepatic haematomas & 3 \\
Intra-peritoneal bleeding & 6 \\
Haemothorax & 4 \\
Subphrenic arterial hemorrhage & 1 \\
Bile duct injury & 26 \\
Biliary stenosis & 8 \\
Biloma combined with infection & 11 \\
Bile leak & 5 \\
Bronchobiliary fistula & 2 \\
Liver abscess & 23 \\
Diaphragmatic hernia & 5 \\
Liver dysfunction & 5 \\
Multiple organ failure & 4 \\
Intractable pleural effusion & 49 \\
Intractable ascites & 10 \\
Tumor implantation & 6 \\
Severe sepsis & 4 \\
Hepato-gastrointestinal fistula & 1 \\
gallbladder perforation & 1 \\
Massive arterioportal fistula & 1 \\
\hline
\end{tabular}

periprocedural time (within 30 days of the thermal ablation) with a mortality of $0.18 \%$. Among the eight patients, four of them died due to multiple organ failure, one died because of infectious shock, two died due to liver dysfunction, and one death happened by acute myocardial infarction after thermal ablation.

The learning curve for thermal ablation of all the 4,363 patients in our central is shown in Figure 1. According to the trend of the learning curve, the experience of thermal ablation can be classified into five stages. The first stage was from the first patients to the $350^{\text {th }}$ patient, called high-risk period. The second stage was from the $351^{\text {th }}$ patient to $1150^{\text {th }}$ patient, called relative stable period. The third stage, named unstable period, was from the $1151^{\text {th }}$ patient to $2400^{\text {th }}$ patient. The fourth and fifth stage

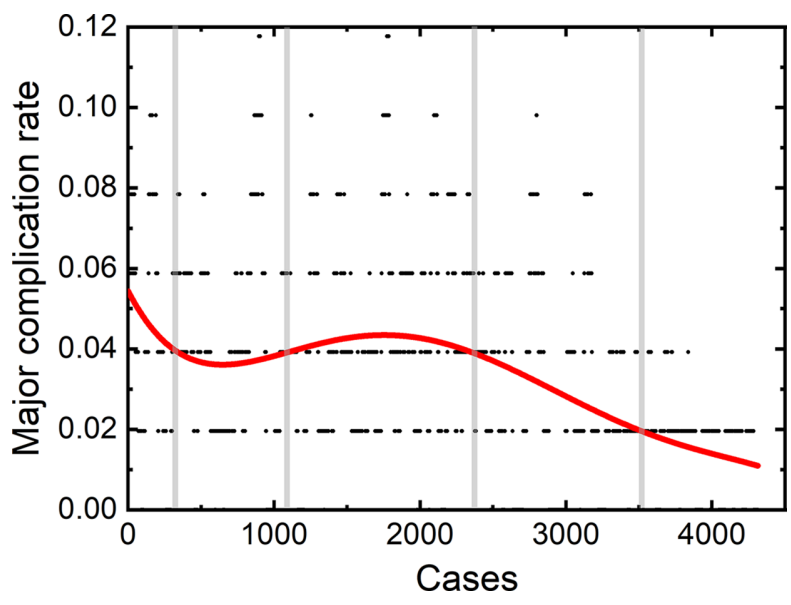

FIGURE 1 | Learning curve for thermal ablation of all the 4,363 patients in our central. was coined proficient period and stable period, from the $2401^{\text {th }}$ patient to $3500^{\text {th }}$ patient and $3501^{\text {th }}$ patient to $4,363^{\text {th }}$ patient, respectively.

Three operators participated in treating the aforementioned patients. X. Jing was the first operator in our central. He started the first thermal ablation since December 2001 with an experience of the technique for 18 years. J. Ding was the second operator and started his first thermal ablation from the $928^{\text {th }}$ patient in our hospital with an experience of 8 years. The third operator was Y. Wang, who starts his first thermal ablation from the $1227^{\text {th }}$ patient, with an experience of 7.5 year for thermal ablation.

A total of 2,170 thermal ablation sessions were performed by the first operator. Among these sessions, 70 patients $(3.23 \%)$ had major complications. 1,104 thermal ablation sessions were performed by the second operator with a major complication rate of $3.35 \%(37 / 1,104)$. The third operator achieved 1,089 sessions, with $36(3.31 \%)$ major complications.

The learning curves of each individual operator were depicted in Figure 2. The learning process can be classified into the highrisk, proficient and stable periods, according to the cut-off values of major complication rates of 4 and $2 \%$. The experience needed to bypass the first stage corresponds to 410,510 , and 440 patients, and the second stage, $1,850,850$, and 870 patients, respectively.

Among the 4,363 thermal ablation sessions, 806 sessions were performed for tumors in difficult locations with a proportion of $18.47 \%$. 223 of the 806 sessions were with tumors adjacent to the large vessels or biliary tract (the first and second branch of biliary duct). Among the above 223 sessions, 159 ablation sessions were assisted with PEI. 57 of the 806 sessions were with tumors close to gallbladder. Hydro-dissection technique was used in 39 of the 57 sessions. 462 of the 806 sessions were with tumors located under liver capsule, including 351 sessions with tumors adjacent to diaphragm and 201 sessions with exophytic tumors. Among the 462 sessions, artificial ascites technique and arterial hydrothorax technique were used in 221 and 123 sessions, respectively. 61 of the 806 sessions were with tumors close to gastrointestinal tract. Artificial ascites technique was used in 45 of the 61 sessions. Artificial ascites technique was used in 3 sessions with tumors close to right kidney. The incidence rate of major complications in patients with a tumor in a difficult location was $6.33 \%(51 / 806)$. The rest 3,557 sessions correspond to 92 major complications with an incidence rate of $2.59 \%$. The learning curve for thermal ablation of tumors in difficult locations was shown in Figure 3.

Among the 806 difficult sessions, 355 ones were performed by the first operator, with a major complication rate of 7.04\%. 217 and 234 sessions were achieved by the second and third operator, respectively. 12 of 217 and 14 of 234 sessions correspond to major complications, with complication rates of 5.53 and $5.98 \%$, respectively. The second and third operator started the thermal ablation for tumors in the difficult location from the $104^{\text {th }}$ and $141^{\text {th }}$ patients, respectively. According to the major complication rates at the cut-off values of 6 and 4\%, a learning curve for thermal ablation of tumors in difficult locations of an individual operator was classified into the high-risk, proficient, and stable 


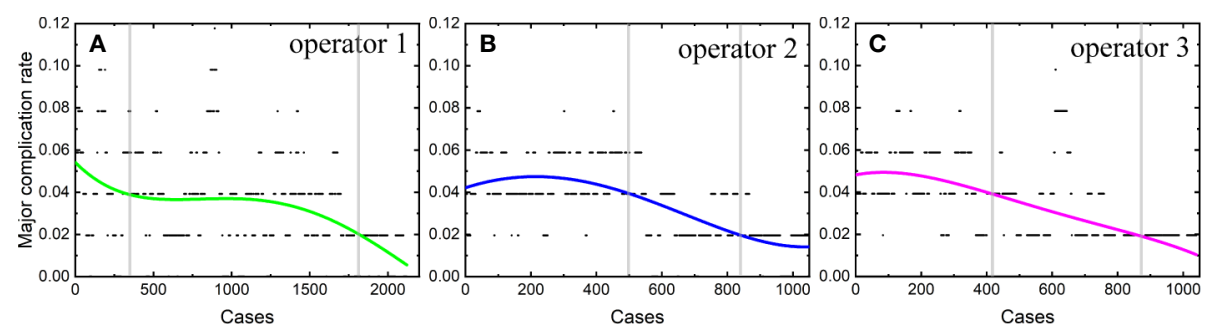

FIGURE 2 | Learning curves of the operator 1 (A), operator 2 (B) and operator 3 (C).

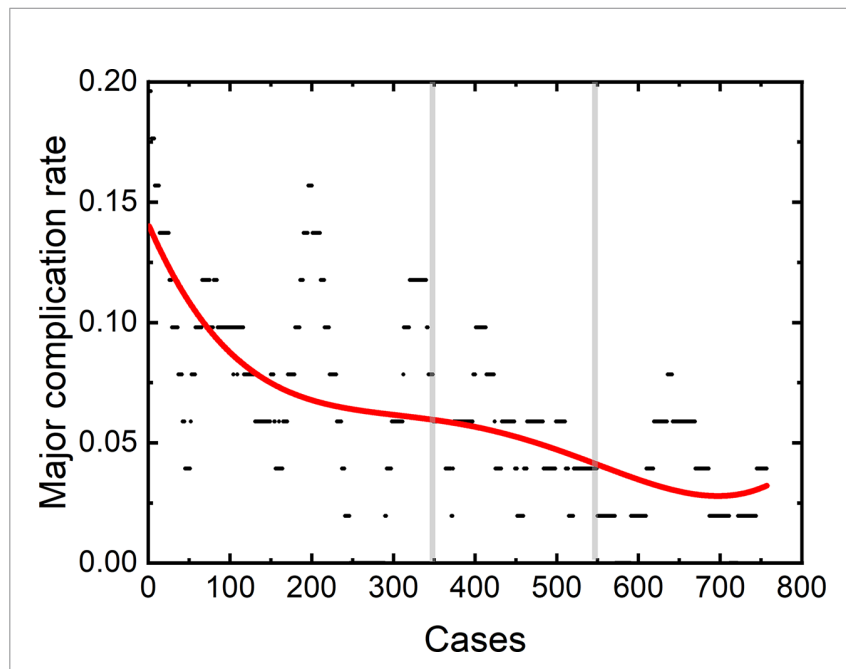

FIGURE 3 | Learning curve for 806 sessions of tumors in difficult locations.

periods (Figure 4). The experience required to bypass the first stage corresponds to 150,130 , and 140 patients and the second, 290,175 , and 185 , for the three operators, respectively.

\section{DISCUSSION}

The major complication rate of our central for the 4,363 radical thermal ablations of liver cancers was $3.27 \%$, similar to those reported in previous studies $(9,22)$. According to the learning curve of individual operators in our hospital, the learning process can be classified into three stages, namely, the high-risk, proficient, and stable periods. The experience required to bypass the first period corresponds to similar number of patients for the three operators, which was not affected by handing-down teaching. However, handing-down teaching can significantly reduce experience needed to bypass the second period, as mirrored by the length of this period of the three operators. The peak value of the complication rate for thermal ablation of tumors in difficult locations is also reduced due to the handing-down teaching.

Recently, thermal ablation is widely used for primary and metastatic liver tumors and is popular with clinician due to its minimal invasion and safety $(23,24)$. Besides, thermal ablation is easy to learn, so that clinician in different professions started to use this therapy to treat liver cancer. In China, thermal ablation can be performed by clinician in the departments of interventional ultrasound, interventional radiography, and hepatobiliary surgery etc. However, the learning process of this technique does not attract the same attention as laparoscopic liver resection, roboticassisted laparoscopic colorectal surgery, and laparoscopic cholecystectomy (25-27). Previous studies mentioned that the complication rates range from 1.3 to $10 \%(10-13)$. Although the risk of complications can be reduced by improving our ablation skills, using assisted methods or developing equipment. Assisted methods and ablation strategy have been reported to achieve complete ablation and reduce major complications in previous studies (28-32). The learning process of this technique has not been well studied. In our study, the learning curve of this
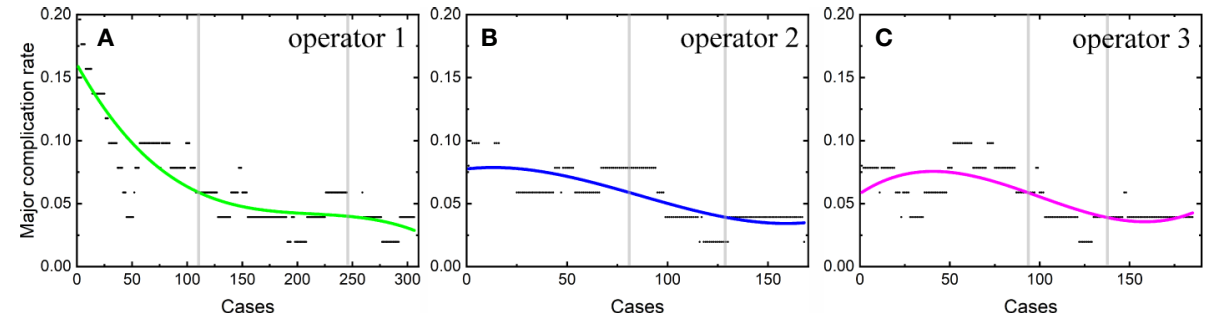

FIGURE 4 | Learning curve for thermal ablation of tumors in difficult locations of the operator 1 (A), operator 2 (B) and operator 3 (C). 
technique has been explored, and the influence of handing-down teaching on the learning process has been analyzed.

The learning curve of 4,363 thermal ablation sessions in our single central shows five stages, namely, the high-risk, relative stable, unstable, proficient, and stable periods. A peak value of major complication rate of $5.5 \%$ appeared in the first stage. Then, the major complication rates decrease. The stable period of our group, with a major complication rate of $2 \%$ similar to a previous study (11), is after the relative stable, unstable, and proficient period. 1,150 patients in the first stage were treated by the first operator only. The major complication rate shows a mild trend of increase in the third stage, which may be caused by the new participants of the second and third operators. The second and third operators started their individual thermal ablation from the $928^{\text {th }}$ and $1227^{\text {th }}$ patients, which corresponds to the third stage $\left(1151^{\text {th }}-2400^{\text {th }}\right)$. After that, the major complication rate decreased rapidly for the following 1,000 patients and became stable at $2 \%$, which indicates that all the operators were skillful enough to perform thermal ablation.

We further plotted the learning curve for thermal ablation of each operator. According to the trends of the curves and the complication rates, we classified the learning process into three stages, according to the cut-off values of major complication rates of 4 and $2 \%$. The first stage is the high-risk period with a major complication rate higher than $4 \%$, the second stage is the proficient period having a rate higher than $2 \%$, and the third stage with a stable complication rate of $2 \%$ is called the stable period. The results of our study demonstrate that the experience corresponding to about 400 to 500 patients were needed to bypass the first period. Under the guidance of handing-down teaching, the experience needed in the first period did not decrease for the second and third operator. Different from the first period, the required experience reduced significantly in the second period by the handing-down teaching. The first operator arrived at the stable period when treating the $1800^{\text {th }}$ patient, while the experience corresponding to only half number of patients was needed for the second and third operator. This result indicates that the handing-down teaching has an important effect on learning thermal ablation.

We found that the risk of major complication highly depends on the location of tumors, in agreement with a previous study (28). Patients with tumors in difficult locations have a high major complication rate, in accordance with previous results $(28,31)$. The major complication was usually caused by (1) puncturing the non-tumor tissues by electrode or antenna, (2) thermal damage. It has been reported that patients with tumors close to biliary duct or with tumors adjacent to diaphragm have a higher major complication rate $(28,33)$. In our study, the major complication rate of patients with tumors in difficult locations is 2.5 times as large as that of patients without a tumor located in difficult locations. Therefore, understanding the learning process of difficult thermal ablation is very important. We calculated the learning curve of 806 difficult thermal ablation sessions. Our results demonstrate that the peak value of major complication rate in the early period of 806 difficult sessions was higher than that of all the sessions (about 14 vs. 5.5\%). Different from the trend of learning curve for all the sessions, the major complication rate for thermal ablation for tumors in difficult locations decreases rapidly and becomes stable at $4 \%$. The second and third operators started their difficult ablation from the $104^{\text {th }}$ and $141^{\text {th }}$ patient with a tumor located in difficult locations, respectively. Besides, the trend of the learning curve was not affected by the participant of the second and third operators. Without any fluctuations, the complication rate on the learning curve for thermal ablations of tumors in difficult locations decreases gradually.

The learning curves for thermal ablations of tumors in difficult locations of each operator were calculated. The learning process was classified into three stages, namely, the high-risk, proficient and stable periods, according to the trend of curve and the cut-offs of complication rates of 6 and 4\%. The handing-down teaching also shows an effect on the second period but a negligible effect on the first period. The experience of thermal ablation needed to bypass the second period were significantly reduced under the guidance of the teacher (the first operator: 290, the second operator: 175, and the third operator: 185). Furthermore, the peak values of major complication rates for thermal ablations of tumors in difficult locations were lower for "students" (the second and third operators) compared with that for the "teacher" (the first operator). The peak values of major complication rates for the second and third operators were about 8 to $9 \%$ compared with $16 \%$ for the first operator. All the above results indicate that thermal ablation for liver cancer is experience-dependent. The handing-down teaching can shorten the learning process and reduce peak value of the major complication rate.

The learning process of thermal ablation for liver cancer presents three stages. The first stage, namely, the high-risk period was the early stage of learning. Both in the learning processes of the team or individual operators, the highest major complication rates appear in the first stage. The experience needed to bypass the first stage of the learning process for all the patients and for patients with tumors in difficult locations was shown in our study. The beginner should pay more attention to the treatment of patients in the first stage. We found that the number of patients relevant to the first stage was stable, which may be determined by this technology itself. Thermal ablation for liver cancer is a minimally invasive treatment and easy-to-learn to perform, which shows low dependence on experience. Besides, the dependence on experience was concealed in the early stage due to the large portion of easy cases enrolled. We thought that the first learning stage of thermal ablation only means "operator can do it" not "operator can achieve it". After the first stage, more cases of patients with tumors in difficult locations were performed in the second stage, namely, proficient stage. The effects of handing-down teaching for thermal ablation are significant in the second stage. Less experience of thermal ablation was needed to bypass the second stage under handing-down teaching and to arrive at the stable period. Except for reducing the need of experience, handing-down teaching can also reduce the peak value of the major complication rate in patients with tumors in difficult locations. However, it should be pointed out that all the operators in our central had an experience of more than 1,000 ultrasound-guided procedures, and all the thermal ablation were performed with the 
free-hand technique, which may have effects on the learning process of thermal ablation. To our knowledge, thermal ablation was performed by two operators with puncture trestle in some centrals $(28,34)$. Thus, the learning curve of thermal ablation in different central may be distinct.

Thermal ablation is not only experience-dependent but also equipment- and assisting method-dependent. In recent years, various assisting methods have been developed to reduce the risk of major complication. For example, PEIT and PTCD with intraductal chilled saline perfusion were used for tumors adjacent to large vessels or biliary duct $(35,36)$. Electrode or antenna deployed parallel to vessels can be also used to avoid damage of large vessels (28). For large tumors with rich blood supply, TACE can be performed before thermal ablation to weaken the influence of "heat sink effect" (37). The invisible lesions on US or CEUS were regarded as a contraindication for percutaneous US-guided thermal ablation. Now such lesions can be ablated under the guidance of US/ CEUS-CECT/CEMRI fusing imaging (38-40). The No-Touch technique is used by inserting multiples electrodes around the periphery of the tumor and activating them sequentially to perform ablation with a sufficient peritumoural margin and decrease the risk of needle-path tumor implantation by avoiding direct puncture of the tumor $(41,42)$. The major complications in our hospital show that some major complications may largely appear in a specific period of time, such as skin burn or diaphragm damage. Among the 143 major complications in our central, only one case of several skin burns happened in the early stage of thermal ablation. The MTC-3CA microwave therapy instrument was performed for this patient. Although a cooledshaft needle was used, the ablation antenna works in parallel with water-cooled circle. We turned on the ablation energy but not water-cooled circle, which caused the skin burn of patients. After that, the manufacturer changed the ablation antenna working in series with water-cooled circle and the skin burn never happens in our hospital. Most of the diaphragm damage also happened in the early stage of thermal ablation for the lack of effective assisting method. When the artificial ascites or pleural effusion technique has been developed, the major complications about diaphragm significantly decreased during the ablation procedure by using such assisting methods. Therefore, advanced equipment and effective assisting methods have the same importance as the experience of thermal ablation for reducing the risk of major complications.

Some limitations present in our study. First, although all the treatments in our central aim to achieve the radical treatment outcome, we focused on the learning curve about the major complication of thermal ablation but not the complete ablation rate or prognosis in this study. Second, considering the

\section{REFERENCES}

1. Heimbach JK, Kulik LM, Finn RS, Sirlin CB, Abecassis MM, Roberts LR, et al. AASLD guidelines for the treatment of hepatocellular carcinoma. Hepatology (2018) 67:358-80. doi: 10.1002/hep.29086

2. European Association for the Study of the Liver. Electronic address: easloffice@easloffice.eu, European Association for the Study of the Liver. similarities of the two types of thermal ablation technologies, i.e., microwave ablation and radiofrequency ablation, they were not analyzed respectively.

\section{CONCLUSION}

The learning process of thermal ablation is classified into the high-risk, proficient and stable periods. The major complication rate of patients with tumors in difficult locations are higher than that of patients without a tumor in difficult locations. The major complication rate is stabilized at $2 \%$ for thermal ablation of all the tumors and $4 \%$ for thermal ablation of tumors in difficult locations. Handing-down teaching can reduce the experience needed to bypass the second period and reduce the peak value of major complication rate for patients with tumors in difficult locations. Our results can help the operators, especially beginners, achieve proficiency in an efficient fashion.

\section{DATA AVAILABILITY STATEMENT}

The datasets generated for this study are available on request to the corresponding author.

\section{ETHICS STATEMENT}

The studies involving human participants were reviewed and approved by Tianjin Third Central Hospital Institutional Review Board. Written informed consent for participation was not required for this study in accordance with the national legislation and the institutional requirements.

\section{AUTHOR CONTRIBUTIONS}

YZ and XJ designed the study and wrote the manuscript. JD and ZQ collected data. HZ, YW, and YW supervised the findings of this study. All authors contributed to the article and approved the submitted version.

\section{FUNDING}

This work was supported the Tianjin Science and Technology Commission (nos. 17ZXMFSY00050 and No.17YFZCSY01070).

3. Elliott R, Ram S, Khanna V. Classification and Current Treatment of Hepatocellular Carcinoma. Am J Intervent Radiol (2018) 2:8. doi: 10.25259/ AJIR-21-2018

4. An C, Li X, Zhang M, Yang J, Cheng Z, Yu X, et al. 3D visualization ablation planning system assisted microwave ablation for hepatocellular carcinoma 
(Diameter >3): a precise clinical application. BMC Cancer (2020) 20:44. doi: 10.1186/s12885-020-6519-y

5. Jiang A-N, Wang S, Yang W, Zhao K, Bai X-M, Zhang Z-Y, et al. The Role of a Curved Electrode with Controllable Direction in the Radiofrequency Ablation of Liver Tumors Behind Large Vessels. Cardiovasc Intervent Radiol (2019) 42:893-904. doi: 10.1007/s00270-019-02182-0

6. Ng KKC, Chok KSH, Chan ACY, Cheung TT, Wong TCL, Fung JYY, et al. Randomized clinical trial of hepatic resection versus radiofrequency ablation for early-stage hepatocellular carcinoma. Br J Surg (2017) 104:1775-84. doi: 10.1002/bjs.10677

7. Shi J, Sun Q, Wang Y, Jing X, Ding J, Yuan Q, et al. Comparison of microwave ablation and surgical resection for treatment of hepatocellular carcinomas conforming to Milan criteria. Jf Gastroenterol Hepatol (2014) 29:1500-7. doi: 10.1111/jgh.12572

8. Ding J, Jing X, Liu J, Wang Y, Wang F, Wang Y, et al. Complications of thermal ablation of hepatic tumours: comparison of radiofrequency and microwave ablative techniques. Clin Radiol (2013) 68:608-15. doi: 10.1016/ j.crad.2012.12.008

9. Maeda M, Saeki I, Sakaida I, Aikata H, Araki Y, Ogawa C, et al. Complications after Radiofrequency Ablation for Hepatocellular Carcinoma: A Multicenter Study Involving 9,411 Japanese Patients. Liv Cancer (2020) 9(1):50-62. doi: $10.1159 / 000502744$

10. Chua JME, Lam YMP, Tan BS, Tay KH, Gogna A, Irani FG, et al. Single-centre retrospective review of risk factors for local tumour progression and complications in radiofrequency ablation of 555 hepatic lesions. Singapore. Med J (2019) 60:188-92. doi: 10.11622/smedj.2019036

11. Livraghi T, Solbiati L, Franca Meloni M, Scott Gazelle G, Halpern EF, Nahum Goldberg S. Treatment of Focal Liver Tumors with Percutaneous Radiofrequency Ablation: Complications Encountered in a Multicenter Study. Radiology (2003) 226:441-51. doi: 10.1148/radiol.2262012198

12. Kong W-T, Zhang W-W, Qiu Y-D, Zhou T, Qiu J-L, Zhang W, et al. Major complications after radiofrequency ablation for liver tumors: analysis of 255 patients. World J Gastroenterol (2009) 15:2651-6. doi: 10.3748/wjg.15.2651

13. Liang P, Wang Y, Yu X, Dong B. Malignant Liver Tumors: Treatment with Percutaneous Microwave Ablation-Complications among Cohort of 1136 Patients. Radiology (2009) 251:933-40. doi: 10.1148/radiol.2513081740

14. Fang C, Cortis K, Yusuf GT, Gregory S, Lewis D, Kane P, et al. Complications from percutaneous microwave ablation of liver tumours: a pictorial review. $\mathrm{Br}$ J Radiol (2019) 92:20180864. doi: 10.1259/bjr.20180864

15. Kasugai H, Osaki Y, Oka H, Seki T, Kudo M. Severe complications of radiofrequency ablation therapy for hepatocellular carcinoma: analysis of 3,891 ablations in 2,614 patients. Oncology (2007) 72:72-5. doi: 10.1159/000111710

16. Moumouh A, Hannequin J, Chagneau C, Rayeh F, Jeanny A, WeberHoltzscherer A, et al. A tamponade leading to death after radiofrequency ablation of hepatocellular carcinoma. Eur Radiol (2005) 15:234-7. doi: 10.1007/s00330-004-2485-z

17. Melikian R, Minocha J. Septic Shock and Death after Microwave Ablation of Hepatocellular Carcinoma in a Liver Transplant Patient with a Bilioenteric Anastomosis. Semin Intervent Rad (2019) 36:137-41. doi: 10.1055/s-00391688430

18. Poon RT, Ng KK, Lam CM, Ai V, Yuen J, Fan ST, et al. Learning Curve for Radiofrequency Ablation of Liver Tumors. Ann Surg (2004) 239:441-9. doi: 10.1097/01.sla.0000118565.21298.0a

19. Yan TD, King J, Sjarif A, Glenn D, Steinke K, Morris DL. Learning curve for percutaneous radiofrequency ablation of pulmonary metastases from colorectal carcinoma: a prospective study of 70 consecutive cases. Ann Surg Oncol (2006) 13:1588-95. doi: 10.1245/s10434-006-9010-3

20. Hildebrand P, Leibecke T, Kleemann M, Mirow L, Birth M, Bruch HP, et al. Influence of operator experience in radiofrequency ablation of malignant liver tumours on treatment outcome. Eur J Surg Oncol (2006) 32:430-4. doi: 10.1016/j.ejso.2006.01.006

21. Burke DR, Lewis CA, Cardella JF, Citron SJ, Drooz AT, Haskal ZJ, et al. Quality improvement guidelines for percutaneous transhepatic cholangiography and biliary drainage. J Vasc Intervent Radiol (2003) 14: S243-6. doi: 10.1016/j.jvir.2010.01.012

22. Yu J, Liang P, Yu X-L, Cheng Z-G, Han Z-Y, Liu F-Y. Comparison of cooledprobe microwave and radiofrequency ablation treatment in incipient hepatocellular carcinoma: A phase III randomized controlled trial with 6- year follow-up. J Clin Oncol (2016) 34:4068-8. doi: 10.1200/ JCO.2016.34.15_suppl.4068

23. Huang Q, Zeng Q, Long Y, Tan L, Zheng R, Xu E, et al. Fusion imaging techniques and contrast-enhanced ultrasound for thermal ablation of hepatocellular carcinoma - A prospective randomized controlled trial. Int $J$ Hyperthermia (2019) 36:1207-15. doi: 10.1080/02656736.2019.1687945

24. Gennaro N, Mauri G, Varano GM, Monfardini L, Pedicini V, Poretti D, et al. Thermal Ablations for Colorectal Liver Metastases. Dig Dis Intervent (2019) 03:117-25. doi: 10.1055/s-0039-1688724

25. Sultana A, Nightingale P, Marudanayagam R, Sutcliffe RP. Evaluating the learning curve for laparoscopic liver resection: a comparative study between standard and learning curve CUSUM. HPB (2019) 21:1505-12. doi: 10.1016/ j.hpb.2019.03.362

26. Bokhari MB, Patel CB, Ramos-Valadez DI, Ragupathi M, Haas EM. Learning curve for robotic-assisted laparoscopic colorectal surgery. Surg Endosc (2011) 25:855-60. doi: 10.1007/s00464-010-1281-x

27. Moore MJ, Bennett CL. The learning curve for laparoscopic cholecystectomy. The Southern Surgeons Club. Am J Surg (1995) 170:55-9. doi: 10.1016/S00029610(99)80252-9

28. Yang W, Yan K, Wu G-X, Wu W, Fu Y, Lee J-C, et al. Radiofrequency ablation of hepatocellular carcinoma in difficult locations: Strategies and long-term outcomes. World J Gastroenterol (2015) 21:1554-66. doi: 10.3748/ wjg.v21.i5.1554

29. Liu F, Yu X, Cheng Z, Han Z, Sun Y, Liang P, et al. Comparison of ultrasonography-guided percutaneous microwave ablation for subcapsular and nonsubcapsular hepatocellular carcinoma. Eur J Radiol (2017) 91:93-8. doi: 10.1016/j.ejrad.2017.04.002

30. Chen S, Peng Z, Lin M, Chen Z, Hu W, Xie X, et al. Combined percutaneous radiofrequency ablation and ethanol injection versus hepatic resection for 2.1-5.0 $\mathrm{cm}$ solitary hepatocellular carcinoma: a retrospective comparative multicentre study. Eur Radiol (2018) 28:3651-60. doi: 10.1007/s00330-018-5371-9

31. An C, Cheng Z, Yu X, Han Z, Liu F, Li X, et al. Ultrasound-guided percutaneous microwave ablation of hepatocellular carcinoma in challenging locations: oncologic outcomes and advanced assistive technology. Int J Hyperthermia (2020) 37:89-100. doi: 10.1080/ 02656736.2019.1711203

32. Ding J, Zhou Y, Wang Y, Jing X, Wang F, Wang Y. Percutaneous microwave ablation of exophytic tumours in hepatocellular carcinoma patients: Safe or not? Liver Int (2017) 37:1365-72. doi: 10.1111/liv.13426

33. Lin M-X, Ye J-Y, Tian W-S, Xu M, Zhuang B-W, Lu M-D, et al. Risk Factors for Bile Duct Injury After Percutaneous Thermal Ablation of Malignant Liver Tumors: A Retrospective Case-Control Study. Dig Dis Sci (2017) 62:1086-94. doi: 10.1007/s10620-016-4312-1

34. Ye J, Huang G, Zhang X, Xu M, Zhou X, Lin M, et al. Three-dimensional contrast-enhanced ultrasound fusion imaging predicts local tumor progression by evaluating ablative margin of radiofrequency ablation for hepatocellular carcinoma: a preliminary report. Int J Hyperthermia (2019) 36:55-64. doi: 10.1080/02656736.2018.1530460

35. Li X, Yu J, Liang P, Yu X, Cheng Z, Han Z, et al. Ultrasound-guided percutaneous microwave ablation assisted by three-dimensional visualization operative treatment planning system and percutaneous transhepatic cholangial drainage with intraductal chilled saline perfusion for larger hepatic hilum hepatocellular $(\mathrm{D} \geq 3 \mathrm{~cm})$ : preliminary results. Oncotarget (2017) 8:79742-9. doi: 10.18632/oncotarget.19275

36. Li M, Li Z, Gao Y, Tian J, Chen M, Dong J. Safety and efficacy of percutaneous radiofrequency ablation combined with percutaneous ethanol injection for hepatocellular carcinoma in high-risk locations. Adv Ultrasound Diagn Ther (2018) 2:5-16.

37. Chen Q-W, Ying H-F, Gao S, Shen Y-H, Meng Z-Q, Chen H, et al. Radiofrequency ablation plus chemoembolization versus radiofrequency ablation alone for hepatocellular carcinoma: A systematic review and metaanalysis. Clin Res Hepatol Gastroenterol (2016) 40:309-14. doi: 10.1016/ j.clinre.2015.07.008

38. Ahn SJ, Lee JM, Lee DH, Lee SM, Yoon J-H, Kim YJ, et al. Real-time US-CT/MR fusion imaging for percutaneous radiofrequency ablation of hepatocellular carcinoma. J Hepatol (2017) 66:347-54. doi: 10.1016/j.jhep.2016.09.003

39. Hakime A, Yevich S, Tselikas L, Deschamps F, Petrover D, De Baere T. Percutaneous Thermal Ablation with Ultrasound Guidance. Fusion Imaging 
Guidance to Improve Conspicuity of Liver Metastasis. Cardiovasc Intervent Radiol (2017) 40:721-7. doi: 10.1007/s00270-016-1561-5

40. Calandri M, Ruggeri V, Carucci P, Mirabella S, Veltri A, Fonio P, et al. Thermal ablation with fusion imaging guidance of hepatocellular carcinoma without conspicuity on conventional or contrast-enhanced US: surrounding anatomical landmarks matter. Radiol Med (2019) 124:1043-8. doi: 10.1007/ s11547-019-01057-1

41. Petit A, Hocquelet A, N'kontchou G, Varin E, Sellier N, Seror O, et al. NoTouch Multi-bipolar Radiofrequency Ablation for the Treatment of Subcapsular Hepatocellular Carcinoma $\leq 5 \mathrm{~cm}$ Not Puncturable via the Non-tumorous Liver Parenchyma. Cardiovasc Intervent Radiol (2020) 43:273-83. doi: 10.1007/s00270-019-02357-9

42. Seror O, N'Kontchou G, Nault J-C, Rabahi Y, Nahon P, Ganne-Carrié N, et al. Hepatocellular Carcinoma within Milan Criteria: No-Touch Multibipolar
Radiofrequency Ablation for Treatment-Long-term Results. Radiology (2016) 280:611-21. doi: 10.1148/radiol.2016150743

Conflict of Interest: The authors declare that the research was conducted in the absence of any commercial or financial relationships that could be construed as a potential conflict of interest.

Copyright (c) 2020 Jing, Zhou, Ding, Wang, Qin, Wang and Zhou. This is an openaccess article distributed under the terms of the Creative Commons Attribution License (CC BY). The use, distribution or reproduction in other forums is permitted, provided the original author(s) and the copyright owner(s) are credited and that the original publication in this journal is cited, in accordance with accepted academic practice. No use, distribution or reproduction is permitted which does not comply with these terms. 